\title{
Educación integral en la infancia: un aula innovadora, exitosa y feliz
}

\author{
Mónica Pilar Cobaleda Estepa
}

\begin{abstract}
Resumen
La educación integral en la infancia es fundamental para desarrollar las capacidades cognitivas, comunicativas, afectivas, sociales, creativas y práxicas de los estudiantes. Por ello, la dinamización de las estrategias de enseñanza-aprendizaje con enfoque holístico adquieren relevancia en todo momento. Este trabajo presenta la estrategia AIEF - aula innovadora, exitosa y feliz- para la educación integral en la infancia con un enfoque en la innovación, lo lúdico, el arte, el desarrollo del pensamiento científico, la inteligencia emocional y el aprendizaje significativo en el proceso formador, que incluye el uso innovador de las tecnologías y su relación con el contexto cultural. Además, se presentan los principios orientadores y un conjunto de didácticas transversales que pueden ser aplicadas directamente o con las adaptaciones de contexto por parte de otros maestros. Esta estrategia permite así, generar procesos donde, tanto el estudiante como el maestro, se renuevan constantemente y, desde su praxis, se hacen conscientes de las transformaciones de su rol que circula entre el aprender y enseñar.
\end{abstract}

Palabras clave: educación integral, desarrollo del pensamiento, arte, lúdica, innovación.

\section{Integral Education in Childhood: An Innovative, Successful and Happy CLASSROOM}

\begin{abstract}
Integral education in childhood is fundamental to develop cognitive, communicative, affective, social, creative and practical abilities of students. For that reason, the dynamization of teaching-learning strategies with a holistic approach acquires relevance. This paper presents the AlEF -an innovative, successful and happy classroom-, a strategy for an integral education in childhood, focused on innovation, playfulness, art, and the development of scientific thought, emotional intelligence and meaningful learning in the training process, which includes the innovative use of technologies and their relationship with the cultural context. Additionally, we present guiding principles and a set of transversal didactics that can be applied directly or with context adaptations by other teachers. Thus, this strategy allows to generate processes where both the student and the teacher are constantly renewed and, from their praxis, they become aware of the transformations of their role, that circulates between learning and teaching.
\end{abstract}

Keywords: integral education, development of thought, art, play, innovation.

Recepción: 06/10/2020. Aprobación: 05/03/2021. http://doi.org/10.22201/cuaieed.16076079e.2021.22.4.11 
Docente en la Institución Educativa Jorge Robledo (IER), Medellín, Colombia.

Magister en Educación, Licenciada en educación preescolar. Docente universitaria en el área de pedagogía y arte en las licenciaturas de educación preescolar, educación física y educación artística. Experta en didácticas de la educación. Conferencista y tallerista en eventos académicos para la primera infancia. Obtuvo la distinción "Maestro Huella" del programa de Licenciatura en Educación Artística, Universidad de San Buenaventura, Medellín, 2015, y la condecoración "Medalla a la Valentía ciudad de Medellín", Decreto 0470, de 2019. Compositora de música infantil y directora del grupo musical Colombia de Colores. Asesora nacional en temas de lenguajes expresivos y resiliencia familiar para el Ministerio de Educación Nacional (MEN) de Colombia, el Instituto Colombiano de Bienestar Familiar (ICBF) y la Organización Internacional para las Migraciones (оIm).

\section{Introducción}

El pensar en una educación con enfoque integral para la infancia es un reto constante para la comunidad docente, pues "no se trata simplemente de transmitir conocimientos, como supuso equivocadamente la Escuela Tradicional, sino de formar individuos más inteligentes a nivel cognitivo, afectivo y práxico" (De Zubiría Samper, 2020, p. 196). Por ello, surgen interrogantes como: ¿de qué manera implementar didácticas asertivas en la integralidad del desarrollo para la infancia?, ¿cuál debe ser la forma de interacción maestro-estudiante para lograr el aprendizaje integral? y ¿cómo aprovechar o generar los recursos didácticos innovadores con mirada holística?

Así, en el presente artículo se retoman diversos avances y transformaciones desde una praxis docente obtenida en un trabajo escolar continuo y que, asimismo, sistematiza un diseño, una adaptación y una aplicación de técnicas y herramientas didácticas, algunas son de carácter propio y otras son adaptadas de modelos pedagógicos afines, con formas de comunicación dinámica y creativa. En esta sistematización, además del desarrollo disciplinar enfocado a la cognición y el pensamiento científico, participan, con fuerza y con igualdad, el sentido de importancia, el arte, la lúdica y la innovación tecnológica. Estos elementos conforman la estrategia un Aula Innovadora, Exitosa y Feliz (AIEF), en función del desenvolvimiento creativo e investigativo tanto del maestro como del estudiante. Este punto es importante, ya que permite al maestro sentirse y ser parte activa del proceso de aprendizaje, y no solo de enseñar. En consecuencia, esto lo anima y lo fortalece en la búsqueda constante de sentido y de trascendencia en los diversos espacios en su aula, y en encuentros mediados por la palabra, la dialogicidad, y la expresividad, tanto individual como colectiva, en el desarrollo holístico del ser estudiante o ser maestro. 


\section{Un aula para la cualificación de la educación integral}

El AIEF Surge como una alternativa para lograr, en el aula, un proceso de enseñanza de aprendizaje placentero, eficaz y holístico, que responda a las necesidades actuales y trascendente de los estudiantes y los maestros. El Alef explica así su nombre:

- Aula: "lugar de encuentro", que trasciende la dimensión física y reconoce al "otro" para enseñar y para aprender juntos.

- Innovadora: usar la creatividad para dar solución a retos formativos que hacen parte de su tiempo, integra tecnologías de la información y la comunicación (TIC) y diversos lenguajes disciplinares.

- Exitosa: al plantear metas al inicio del año escolar, en consonancia, con las habilidades para la vida.

- Feliz: emplea la lúdica, el arte y la imaginación para lograr estados de felicidad y placidez al aprender.

El AIEF parte de la premisa que la integración de elementos holísticos disciplinares pueden tratarse, fácilmente, dentro de las didácticas y la cotidianidad escolar. Se entiende al aprendizaje holístico como el que transforma vivencias y experiencias transdisciplinares en la adquisición del conocimiento, en sintonía con las dimensiones físicas y espirituales del sujeto, en vínculo con el planeta que habita y los seres que le rodean (Gallegos Nava, 2015). Asimismo, propone el uso innovador de las tic en relación con la cultura para interactuar con distintos lenguajes, mientras aporta al desarrollo del ser y mantiene el sentido de lo humano. La estrategia Alef se estructura con principios y didácticas transversales presentados en la imagen 1.

\section{AIEF: aula innovadora, exitosa y feliz}

Imagen 1. Estructura del AIEF. AMAT: Aprendizaje de las Matemáticas Apoyada en TIc. Elaboración propia.

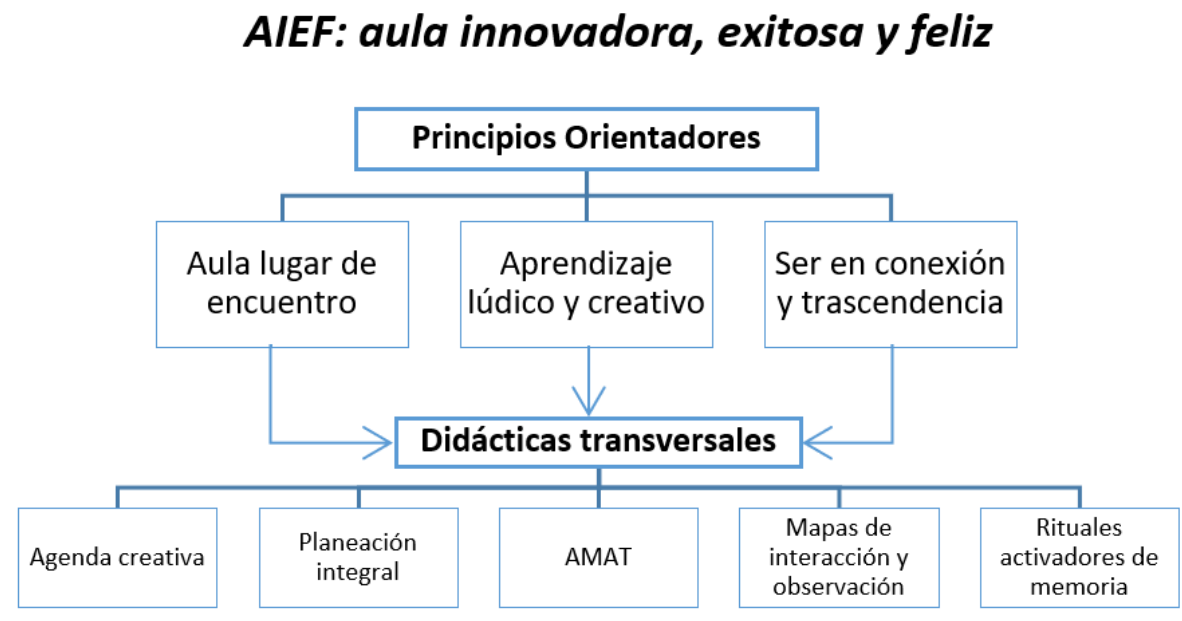




\section{Principios orientadores}

Los principios orientadores del AlEF invitan a la construcción de una relación empática entre el maestro y el estudiante para ver el aula más que un sitio de trabajo agobiador, e invita a verla como un lugar para la sorpresa donde se puede reír, jugar, expresarse, enseñar y aprender sin temor, en alteridad. Estos principios son:

- Aula, lugar de encuentro. El aula como un espacio o un lugar físico y concreto, pero también, un lugar mental, o virtual, donde en el encuentro media el aprender. Esto convierte en aula y en encuentro, cualquier lugar donde estén el rol del enseñante y del aprendiz, y donde haya asombro, curiosidad, alegría y calma en la adquisición de metas formativas.

- Aprendizaje lúdico y creativo. Comprende la lúdica como el disfrute y el placer por la vida (liménez Vélez, 2013); enriquece las didácticas desde el jugar para aprender, por ejemplo, al realizar juegos de palmas para memorizar nociones; jugar aprendiendo, al ejercitar habilidades motrices, emocionales o mentales mientras se juega; y aprender a jugar, al apropiarse y transformar, creativamente, las formas del juego, según los intereses de quienes juegan.

- Ser en conexión y trascendencia. Este principio propone reconocerse y reconocer al otro a través del lenguaje integral que genera el maestro, ya sea con formas gestuales, con la palabra o con su entonación, posturas físicas y mentales. De igual manera, incluye el escuchar y el lenguaje discursivo, elementos del saber ancestral y cultural, según Gallegos Nava, para una sintonía con lo universal (2015).

\section{Didácticas transversales}

Desde estos principios, la estrategia alef presenta unas didácticas transversales, que trascienden esa sensación mecanicista que a veces acompaña a la rutina escolar, y cualifican la práctica docente desde el potencial creativo y transformador. Estas son la agenda creativa, el diseño de planeación integral, la metodología para el Aprendizaje de las Matemáticas Apoyada en TIC (AMAT), Ios mapas de interacción y observación, y los rituales activadores de memoria.

\section{Agenda creativa}

Describe actividades para la rutina diaria que concientizan al niño para sentirse parte de un grupo, aún si se trabaja virtualmente. Aparta al maestro de la acción de controlar el grupo, y propone la construcción social y natural de ambientes de aprendizajes más enriquecedores. 


\section{Partes de la agenta creativa}

- Saludo y za quién extrañamos hoy?: remplaza el pasar lista por las formas de percepción de presencia y ausencia del otro, además, visibiliza los vínculos entre compañeros y utiliza la herramienta mapas de interacción y observación grupal descritos posteriormente.

- Meditación u oración: la meditación fomenta el autoconocimiento y el desarrollo de potencialidades mentales; la oración, en libertad de culto, genera conexión espiritual para la trascendencia.

- Cantar: para generar placidez, alegría y estimular procesos de pensamiento, memorización, habilidades artísticas innatas y la creatividad.

- Bitácora del sentir y pensar: fortalece la escritura en construcción colectiva de contenidos mientras se le da sentido a cada letra, trazo o frase registrada en una libreta, lo que lo transforma en un cuaderno filosófico que, desde la dialogicidad, genera reflexión y metacognición (ver imagen 2).

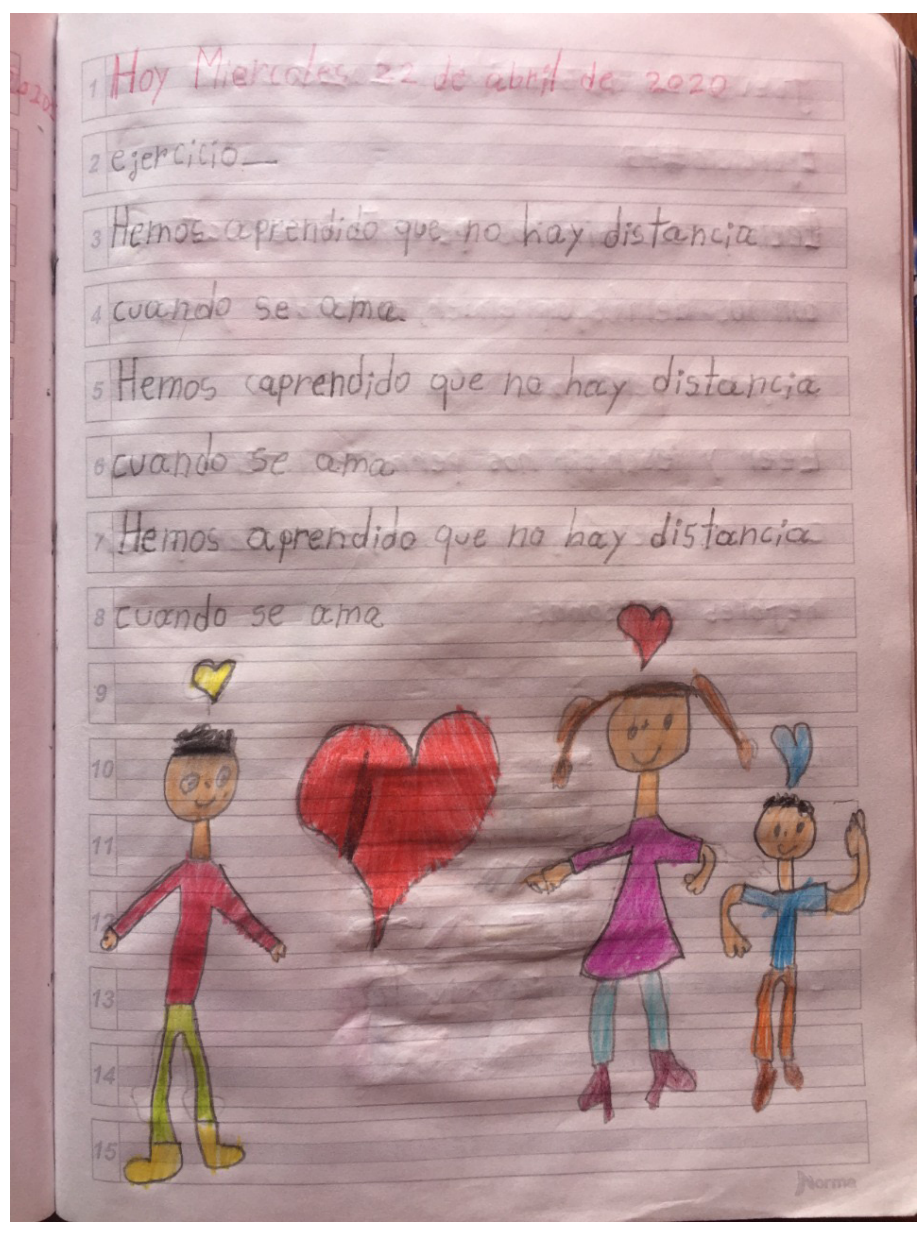


- Es tiempo de...: práctica lúdica oral del maestro que conecta, desde la rítmica de la palabra, distintos momentos y rutinas, tanto planeadas como inesperadas.

- Momento cultural: espacio de 15 minutos para compartir talentos, investigaciones o temáticas que amplían la apreciación estética y cultural.

- Frase de cada día de la semana: promueve frases que fortalecen la cohesión grupal en contexto de los valores éticos (ver imagen 3).

Imagen 3. Agenda creativa. Autoría propia con el dibujo de Hayle Fonseca, 2020.

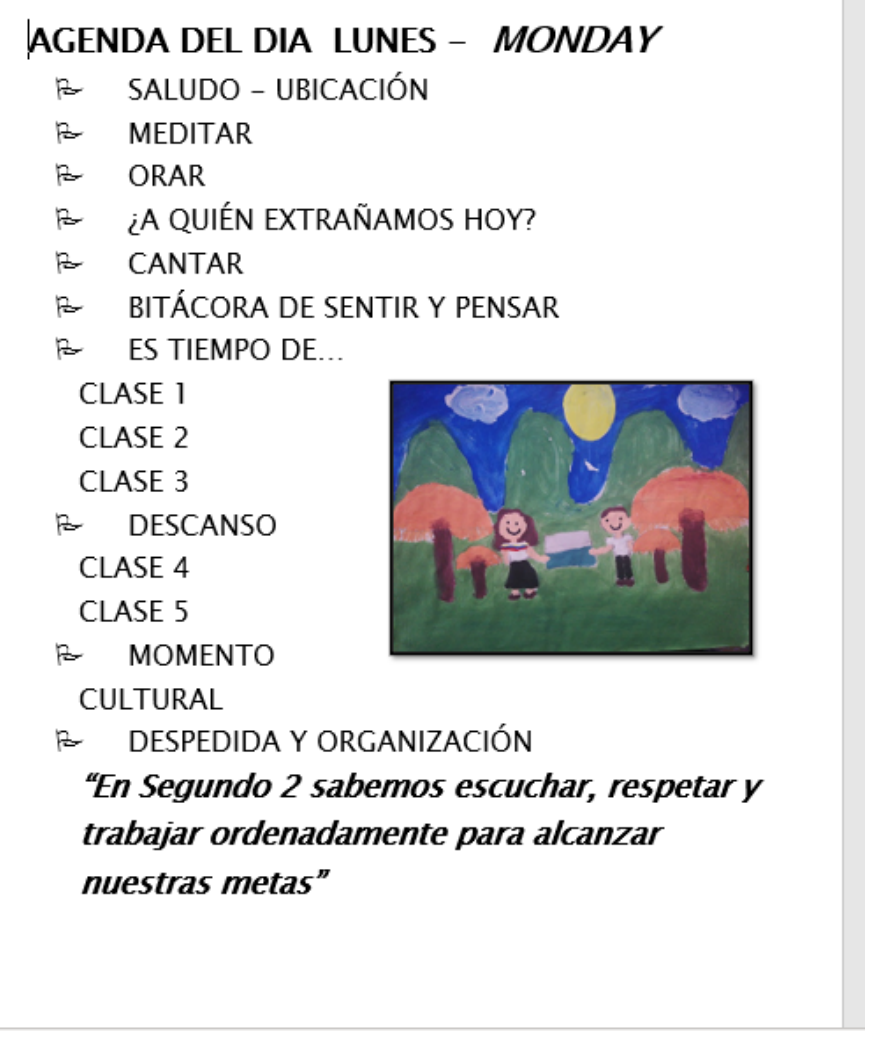

\section{Diseño de planeación integral}

Esta didáctica estructura las clases o los "encuentros", reflejando su concepción integral desde estas perspectivas:

- Aprendizaje holístico, lúdico, creativo, artístico.

- Desarrollo del pensamiento y espíritu investigador.

- Contenidos en contexto.

- Identificación de fuentes de conocimiento.

- Apropiación de rutinas, autonomía en el aprendizaje, e inteligencia emocional. 
- Reflexión, argumentación, diálogo en espacios de convivencia.

- Gestión de didácticas creativas y trabajo colaborativo.

- Proceso evaluativo y seguimiento en el lugar.

\section{Elementos del diseño de la planeación integral}

- La pregunta: se plantea una pregunta para introducir el tema, que trasciende la mirada positivista de hallar respuestas "técnicamente correctas". Tiende más a ser un puente con lo sensible, con lo emocional, con lo imaginativo y con lo divertido del aprender. De todas las respuestas, se le reconoce al autor (estudiante, docente, fuente) fomentando, así, la alteridad, el autoestima y el uso de fuentes investigativas. Esto propicia nuevas hipótesis, comprobaciones concretas o abstractas, activa la imaginación, provoca deseo de conocer, motiva desde vivencias y/o evoca conocimientos previos. Un ejemplo de esto se puede observar en la imagen 4.

Imagen 4. Pregunta y respuestas. Leyre Marulanda, 2017.

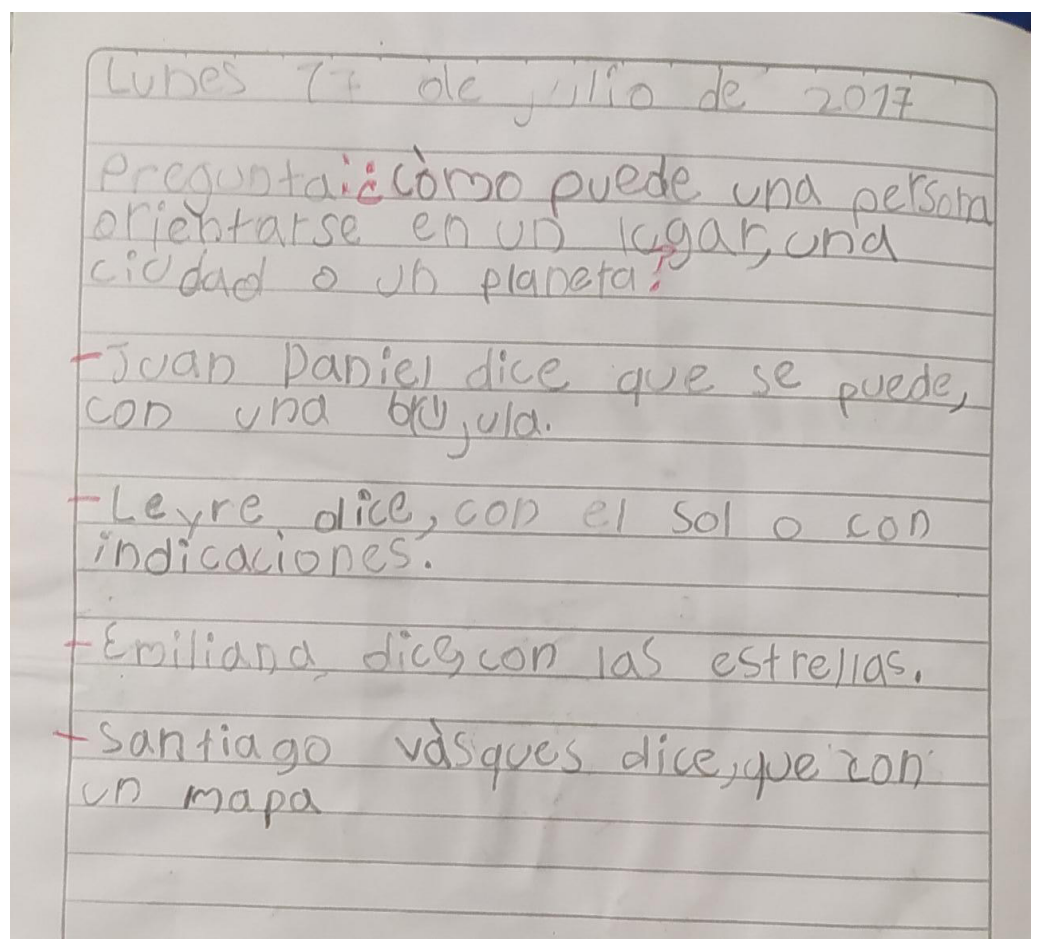

- Actividades integrales de aprendizaje: buscan que el docente y el estudiante, hallen un sentido a cada actividad, la disfruten y se diviertan en el proceso, pues como propone Freire, juntos se aprende mejor (2012). Cada experiencia diseñada, a criterio distributivo del docente, contiene elementos de conexión multisensorial del Diseño Universal del Aprendizaje (DUA), desarrollo de habilidades del pensamiento, uso de lenguajes artísticos y lúdicos mediados por un lenguaje que comprende la inteligencia emocional. Esto es transversalizado con procesos de lectura y escritura integral, una forma comunicativa que 
circula entre la interpretación de signos, formas, sonidos, gestos, e imágenes dentro de un contexto cultural.

- Idea para recordar: es una frase escrita y descriptiva para sintetizar lo aprendido, como construcción conceptual para generar la cultura de memorización con significado.

- Evaluación: encuentro de diálogo con enfoque reflexivo donde cada estudiante o de manera grupal se expresa sin temor al señalamiento por errores o dificultades, y son reconocidos por sus logros.

- Orientaciones al maestro: enriquece el campo conceptual del docente. Describe consejos prácticos o sugerencias didácticas que surgen de procesos investigativos al interior de la institución educativa; aportes desde el acompañamiento directivo al quehacer docente hasta la lectura de contexto en consonancia con posturas teóricas que los docentes de grado consideren importantes.

\section{Metodología para el Aprendizaje de las Matemáticas Apoyada en TIC}

El AIEF adopta una metodología para la enseñanza y el aprendizaje de las matemáticas, con una mirada holística, donde considera tres enfoques: el cognitivo, lúdico-emocional y de integralidad.

El enfoque cognitivo desarrolla la adquisición de las nociones matemáticas desde el pensamiento concreto, la representación pictórica y la representación simbólica en consonancia al pensamiento de Bruner (1995). Además, considera la evolución del pensamiento concreto al simbólico u operaciones formales (Piaget y Inhelder, 2007), lo cual incluye los diferentes grados de complejidad nocional. Así mismo, relaciona esta función simbólica vital para la formación integral del ser, desde elementos del arte y la cultura, como parte de las prácticas cotidianas relacionadas con el pensamiento matemático (Gardner, 2005, p. 234). Un ejemplo de ello puede verse al adquirir la noción de seriación y conteos, cuando el niño parte de juegos corporales, mientras salta de dos en dos entre objetos similares, como sus cuadernos, pasa a representar, pictóricamente, el juego, luego, enumera los elementos saltados y por último, completa series empleando la notación numérica.

El enfoque lúdico-emocional considera "el aprender con placer", "valorar el error como experiencia" y "jugando se aprende". Busca la placidez en disposición intrínseca y extrínseca para el aprendizaje; de igual manera, pretende que el reír sea parte de las acciones, como preguntar para solucionar dudas, donde los aciertos y desaciertos son oportunidades de autoconocimiento y autosuperación, mientras se asume el error con tranquilidad; es decir, hacer del acto de aprender algo divertido. Goleman lo sustenta así: "el buen humor, mientras dura, favorece la capacidad de pensar con flexibilidad y con mayor complejidad, haciendo que resulte más fácil, encontrar soluciones a los problemas, ya sean intelectuales o interpersonales" (2010). 
Imagen 5. Pensamiento simbólico/enfoque lúdicoemocional en estudiantes de $2^{\circ}$

(2019)
El enfoque de integralidad se correlaciona con el diseño de la "planeación integral"yarticulaexperiencias disciplinares, la participaciónyla multisensorialidad. Transversaliza, desde los procesos de lecto-escritura que hacen parte del saber matemático, la aplicación de lo aprendido y la resolución de problemas en contexto. Igualmente, trabaja actividades de registro y memorización con formas de procesamiento de la información a nivel visual, táctil, o auditivo, entre otras (ver imagen 5).

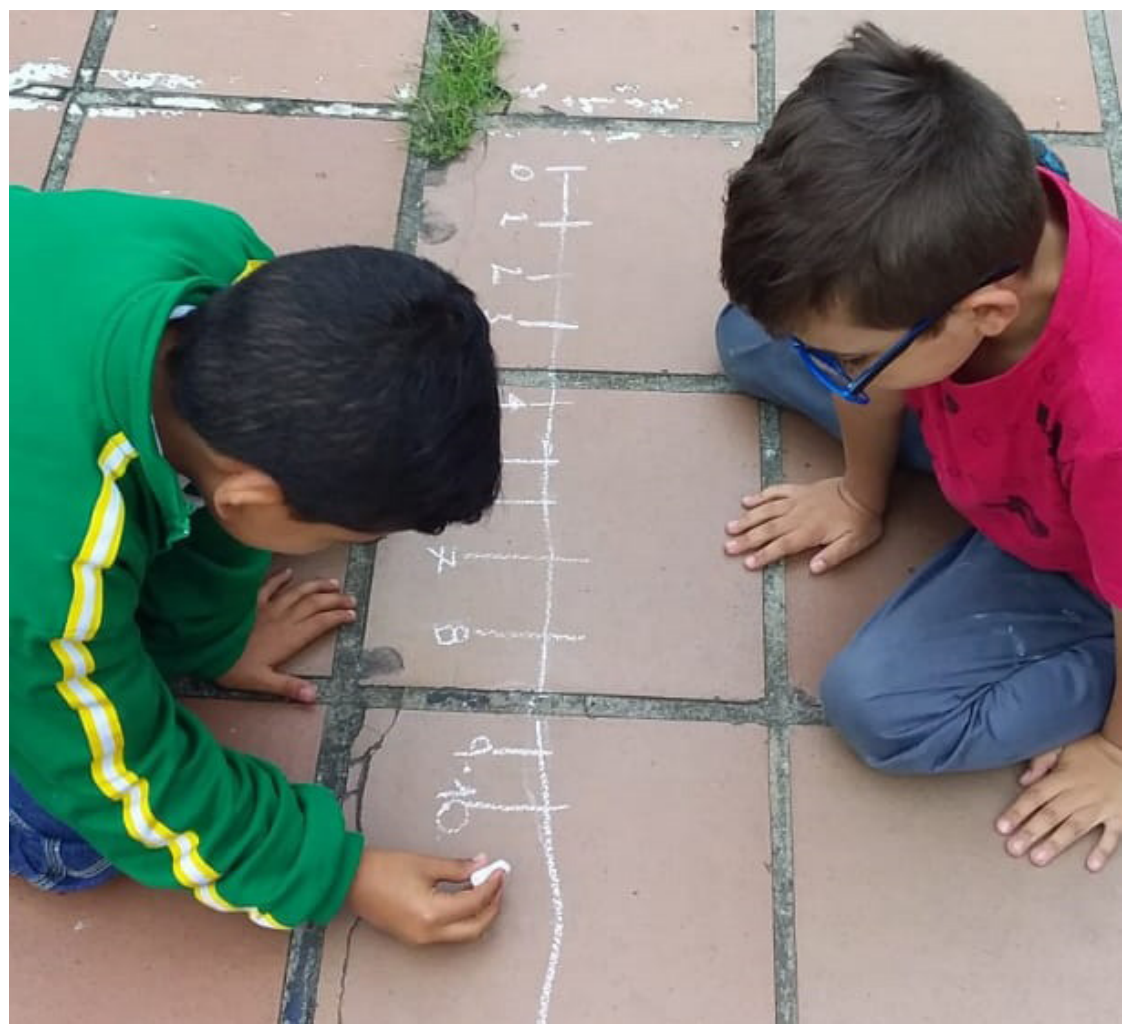

Esta metodología emplea un diseño original de actividades en un ambiente virtual de aprendizaje matemático, para el afianzamiento de habilidades, transversalizadas con áreas como el lenguaje; con narrativas vinculadas a la expresión creativa, artística y poética; las ciencias naturales, la ética, la formación en valores y la lúdica. Esto fortalece el rol del maestro como motivador desde el uso del lenguaje empático hasta conectarlo con el lenguaje matemático; también, refuerza al maestro como integrador que emplea los contextos de aprendizaje de los diferentes discursos del aprendizaje matemático; y, asimismo a un maestro observador porque capta, en cada estudiante, sus características individuales para lograr las metas propuestas, medibles y alcanzables respecto al dominio de nociones y conceptos.

\section{Mapas de interacción y observación}

Estos mapas hacen un registro en el lugar y tiempo real, para sistematizar las características observadas en los estudiantes en función del aprendizaje y del 
desarrollo integral. Exponen Vallés Arándiga y Vallés Tortosa "gran parte del aprendizaje social está favorecido por la observación de las ejecuciones reales de los demás y de las consecuencias que tales actuaciones les comportan" (2000, p. 68). Así, identifican afinidades en las relaciones que fortalecen el trabajo por pares, el cual recibe el nombre de identificación de sinergias focalizadas y pares creativos, basado en la teoría de campo de Kurt Lewin (1988). Además, estos mapas permiten conocer al grupo, no controlarlo, pues "el sentido que puede tener el análisis de las características del estilo individual de aprendizaje es ayudar a desarrollar aquellas estrategias que lleven a un rendimiento en el aprendizaje más eficaz" (Rose et al., 2003, p. 185).

\section{Rituales activadores de memoria}

Son prácticas artísticas, culturales y lúdicas para generar cohesión y recordación. Huizinga las posiciona como fuentes de significación simbólica en la visión estética de las subjetividades y las intersubjetividades conectadas con la inteligencia emocional que da elementos resilientes para la vida (2008), donde "las emociones positivas (felicidad, alegría, esperanza, optimismo...) mantienen y recuperan el equilibrio del organismo, ejercen efectos curativos" (Vallés Arándiga y Vallés Tortosa, 2000), mientras que las emociones negativas, como el enojo, la ira o la depresión, generan toxicidad en el organismo. Precisamente, los rituales de encuentro, festejo o reparación son los facilitadores de este proceso autosanador.

\section{Conclusión: educación integral, el reto de actuar}

La integralidad o mirada holística de la enseñanza se enriquece con las nuevas participaciones epistemológicas y discursivas que amplían las posibilidades de acción y praxis de los maestros dedicados al trabajo con la infancia. Si la escuela tiene como obligación "enseñarnos a pensar mejor, amar mejor y actuar mejor" (De Zubiría Samper, 2020), la educación integral requiere mayor visibilidad y realización al interior de las aulas; pues es urgente propiciar espacios para la formación de un ser humano consciente de sus capacidades y posibilidades creativas y transformadoras del mundo que habita. Así, es posible preguntarse: ¿qué pasaría, si las aulas de clase de los niños, sean de carácter virtual o físico, apuntan, primordialmente, a ser espacios de felicidad y tranquilidad para el aprendizaje?; ¿qué sucedería si los estudiantes vieran que su maestro, docente o tutor disfrutar tanto como ellos del enseñar y del aprender?; ¿cómo sería el ambiente de clase en un lugar donde no se sintiera miedo de tener habilidades distintas a los demás y se entendiera al fracaso o al éxito como parte del aprendizaje?. Por tanto, entender cómo y qué aprenden los niños de cada generación, identificar para qué lo aprenden desde un enfoque de autonomía y pensamiento crítico, demanda un análisis continuo del maestro, quien cumple una función irremplazable, pues es quien le abre la puerta a la niñez a ese mundo de aprendizajes holísticos. 
El jugar no solo permite la expresión libre del niño ante su deseo de aprender, también, lo une con la información concreta, histórica y trascendente de su ámbito cultural, mientras realza un componente ineludible de la educación integral como lo es el campo lúdico del ser humano. Desde esta perspectiva, la estrategia AIEF pone al maestro en una postura proactiva y transgresora, en vez de colocarlo en una zona de confort que, con frecuencia, lo mecaniza, y le permite expresarse desde sus capacidades humanas a la par que ejerce su trabajo. Al hacer de la formación integral una disposición cotidiana, le permite renovar su praxis dándole la oportunidad de resignificar su ejercicio, no solo desde un reconocimiento social o laboral, sino propio.

\section{Referencias}

- Bruner, J. (1995). Desarrollo cognitivo y educación (2. a ed.). Morata.

* De Zubiría Samper, J. (2020). Los modelos pedagógicos. Hacia una pedagogía dialogante. Magisterio.

* Freire, P. (2012). Pedagogía del oprimido (2. ${ }^{a}$ ed.). Siglo xxI.

* Gallegos Nava, R. (2015). Educación holista. Pedagogía del amor universal. Fundación internacional para la Educación Holista.

* Gardner, H. (2005). Arte, mente y cerebro. Una aproximación cognitiva a la creatividad. Paidós Ibérica.

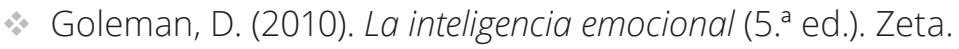

* Huizinga, J. (2008). Homo ludens. FCE.

* Jiménez Vélez, C. A. (2013). La lúdica y los nativos digitales. Lúdica Pedagógica, 1(18), 49-57. https://doi.org/10.17227/01214128.18ludica49.57

* Lewin, K. (1988). La teoría del campo en la ciencia social. Ediciones Paidós Iberica, S.A.

* Piaget, J. y Inhelder, B. (2007). Psicología del niño. Ediciones Morata.

* Rose, R., Florian, L., Tilstone, C. y Cardona Moltó, M. C. (2003). Promoción y desarrollo de prácticas educativas inclusivas. Fundamentos.

* Vallés Arándiga, A., y Vallés Tortosa, C. (2000). Inteligencia emocional. Aplicaciones

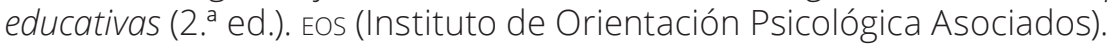

\section{Agradecimientos}

Agradezco el apoyo de la Institución Educativa Jorge Robledo (IEJR) de Medellín, Colombia, a mis colegas, familias y estudiantes que aportaron y disfrutaron de este trabajo. 


\section{Cómo CITAR ESTE ARTículo}

* Cobaleda Estepa, Mónica Pilar. (2021, julio-agosto). Los últimos serán los primeros: la importancia de los hablantes de herencia. Revista Digital Universitaria (RDU), 22(4). http://doi.org/10.22201/cuaieed.16076079e.2021.22.4.11 